\title{
Novel fabrication of a laccase biosensor to detect phenolic compounds using a carboxylated multiwalled carbon nanotube on the electropolymerized support
}

\author{
SHAHAD ABDUL RASOL ALBAYATI ${ }^{1}$, SOHEILA KASHANIAN ${ }^{2,3, *}$, MARYAM NAZARI ${ }^{1,3}$ \\ and SOMAYEH REZAEI ${ }^{1,3}$ \\ ${ }^{1}$ Faculty of Chemistry, Razi University, Kermanshah 67149, Iran \\ ${ }^{2}$ Faculty of Chemistry, Sensor and Biosensor Research Centre (SBRC) and Nanoscience and Nanotechnology Research \\ Centre (NNRC), Razi University, Kermanshah 67149, Iran \\ ${ }^{3}$ Nano Drug Delivery Research Centre, Faculty of Pharmacy, Kermanshah University of Medical Sciences, Kermanshah \\ 6715847141, Iran \\ *Author for correspondence (kashanian_s@yahoo.com)
}

MS received 14 September 2018; accepted 18 January 2019; published online 3 June 2019

\begin{abstract}
Biosensors research is one of the fastest growing fields in which tens of thousands of papers have been published over the years; even more, numerous biosensors have been developed for the detection of phenolic compounds, such as catechol which reacts with an appropriate enzymatic bioreceptor like laccase. A biosensing electrode for catechol detection was investigated by covalent immobilization of laccase on a glassy carbon electrode modified by conducting polymers built of poly(3,4-ethylenedioxythiophene), gold nanoparticles and carboxylated multiwalled carbon nanotubes. The fabrication process of the sensing surface was investigated by Fourier transform infrared spectroscopy, scanning electron microscopy and electrochemical procedures. The electrochemical results demonstrate that the enzyme was immobilized covalently onto the modified glassy carbon electrode by the interaction between carboxyl groups of the carboxylated multiwalled carbon nanotubes and laccase. The biosensor demonstrates a direct electron transfer between the electrode and immobilized laccase. Under optimum conditions, it presented two linear responses in the range of $0.1-0.5$ and $11.99-94.11 \mu \mathrm{M}$. The limits of detection were found to be 0.11 and $12.26 \mu \mathrm{M}$.
\end{abstract}

Keywords. Biosensor; laccase; poly(3,4-ethylenedioxythiophene); phenolic compounds.

\section{Introduction}

There are several interesting features of biosensors making us select them as monitoring tools, such as simplicity, accuracy, reliability and reasonable cost determination of various analysts, as well as the fact that they work as an efficient analytical tool in the state control of food, high sensitivity and selectivity $[1,2]$. An important factor in a biosensor's construction is that effective enzyme immobilization and some methods, such as sol-gel [3] and Langmuir-Blodgett thin film [4] are common [5,6]. Enzymes are proceeding into all chemical reactions that happen under temperate conditions due to their diversity, efficiency and specific catalysts [7]. Some important parameters have a great effect on sensor efficiency including the properties of surface, the protection of protein three-dimensional structure and the electrode and enzyme interactions [8].

In the last two decades, fabrication of different biosensors using conducting polymers $(\mathrm{CP})$ has been studied widely owing to their redox, optical, mechanical and electrical properties [9-12]. CPs are convenient materials for enzyme immobilization since they show high operational stability and fast response [13]. However, one of the more preferred methods is electropolymerization due to the controlling of films' thickness and possibility to get homogeneous films directly on the surface of the electrode [14]. Heteroaromatic thiophene has poor solubility, and therefore, its substituted derivatives were synthesized. The thiophene derivative, 3,4-ethylenedioxythiophene (EDOT) is most often used for synthesizing a CP [15]. Poly(3,4-ethylenedioxythiophene) (PEDOT) demonstrated some attractive properties like high conductivity ( $c a .300 \mathrm{~S} \mathrm{~cm}^{-1}$ ) [9].

Nanomaterials have good catalytic and conductivity properties; these make them convenient to act as 'electronic wires' to promote the moving of an electron among the biodevice and the surface of the electrode [16]. In many of the studies, it was shown that the incorporation of nanomaterials improves the overall performance of the enzymatic biosensor, principally with gold nanoparticles (AuNPs) and carbon nanotubes (CNTs) [17-19]. In the material science of nanotechnology, specific attention has been given to CNTs due to their wonderful mechanical and electrical properties [20]. Recently, they received remarkable attention as promising nanoelectric devices based on carbon [21]. They 

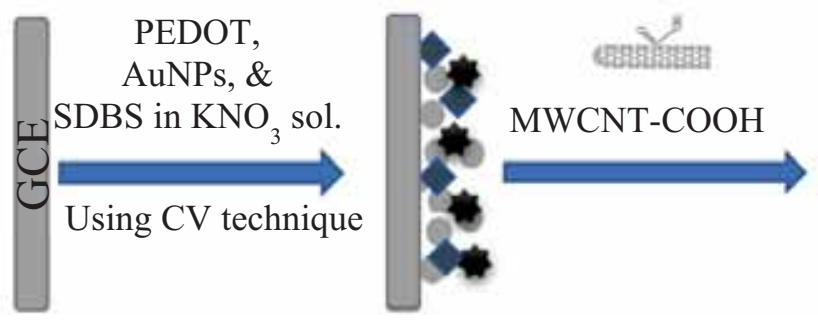

Scheme 1. The steps of proposed Lac biosensor fabrication.
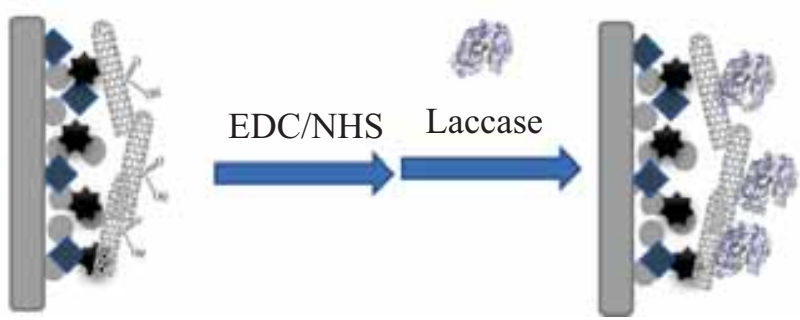

can be used effectively as electrochemical sensing devices due to their properties, such as high thermal conductivity, great surface-to-volume ratio and improved electron transfer [22]. CNTs with functional groups supply a convenient surface for the enzyme's immobilization [23]. Immobilization of the enzyme occurs on the transducer to permit a fast charge transfer and to ensure a sensitive and rapid reply, since they can act as electrical connectors between the biomolecule redox centres and the electrodes [24,25]. An extensive range of sensor constructions have been expanded using paste electrodes [26], and glassy carbon electrodes (GCEs) modified by CNTs and metal NP-modified CNT electrodes. Hence, many literatures have illustrated that metal NPs, semiconductor NPs and metal oxides have been commonly used to alter CNTs [27]. AuNPs have got the greatest attention for biosensor applications [28] due to their advantages, such as the best transfer of mass, more available sites for reaction and effect of optical aggregation/dispersion. The attachment of AuNPs to the surface of electrode is very important for developing electrochemical biosensors [29].

For a long time, laccase (Lac) is the most important part for biosensor fabrication [30] which has been considered, because of its ability to enable oxidation of numerous substrates [31,32]. It can oxidize para-and ortho-diphenol groups ascorbate and aromatic amines [33]. Phenolics are found in many fruits and vegetables. Nevertheless, some phenols are toxic materials and global pollutants that come to the natural waters from chemical industrial waste, including pharmaceuticals, coal refineries, production of petrochemicals, resins, textiles, pulp and paints [27]. Li et al [34] fabricated a biosensor by Lac immobilization with silica spheres on the multiwalled carbon nanotube (MWCNT)-doped screenprinted electrode surface and the results revealed that a high loading of Lac and good electrocatalytic activity were found, due to the good biocompatibility, large specific area and porous structure of MWCNTs and silica spheres. In another work, the improved method was employed for horseradish peroxidase immobilization by its covalent bonding to functionalized MWCNTs; it showed a selective, linear, precise and accurate biodevice for dopamine [35].

In this research, PEDOT, AuNPs and sodium dodecyl benzene sulfonate (SDBS) have been used as a matrix and were electrodeposited on a GCE. After carboxylated MWCNTs (MWCNT-COOH) deposition and Lac immobilization, the biosensor was used for catechol detection. According to scheme 1, the steps of biosensor construction are shown.

\section{Experimental}

\subsection{Materials and reagents}

Lac $\left(\mathrm{EC}=1.10 .3 .2\right.$, from Trametes versicolor, $\left.21.8 \mathrm{U} \mathrm{mg}^{-1}\right)$, $N$-hydroxysuccinimide (NHS) and 1-ethyl-3-(3-dimethylaminopropyl)carbodiimide (EDC) were acquired from Sigma, Aldrich. Lac was used without further purification. Catechol was purchased from Merck, and its stock solutions (0.01 M) were prepared in water. $\mathrm{HAuCl}_{4}$ and EDOT were purchased from PubChem and Tokyo chemical industry, respectively.

\subsection{Apparatus}

Differential pulse voltammetry (DPV) and cyclic voltammetry $(\mathrm{CV})$ were performed with a three-electrode cell connected to a Sama 500 electro analyser system. The GCE was selected as a working electrode. A Pt rod and an $\mathrm{Ag} / \mathrm{AgCl}$ electrode (saturated $\mathrm{KCl}$ ) were applied as counter and reference electrodes, respectively. Scanning electron microscopy (SEM) and Fourier-transform infrared (FTIR) spectroscopy were used to characterize the electrode surface and enzyme immobilization.

\subsection{Biosensor fabrication}

A GCE was polished with alumina slurries and fine emery paper followed by washing completely with deionized water, and after that it was dried at room temperature. Then, in a $\mathrm{KNO}_{3}$ solution $(0.1 \mathrm{M})$ that composed of EDOT $(0.01 \mathrm{M})$, SDBS $(500 \mu \mathrm{M})$ and $\mathrm{HAuCl}_{4}(100 \mu \mathrm{M})$, the electrode was treated under $\mathrm{CV}$ from -0.6 to $1.2 \mathrm{~V}$ (vs. $\mathrm{Ag} / \mathrm{AgCl}$ ) for 10 cycles (at a scan rate of $0.05 \mathrm{~V} \mathrm{~s}^{-1}$ ) to obtain the AuNPs-SDBS-PEDOT/GCE. Figure 1 displays the CVs and deposition of polymer, AuNPs, and SDBS on the electrode surface and also the surface electroactivity due to reduction and oxidation peaks. According to the literature, the redox peaks are related to the oxidation and reduction of PEDOT that appeared in figure 1. In aqueous media, there are several redox peaks, but in acetonitrile and organic solutions, there are just one anodic and one cathodic peaks. 


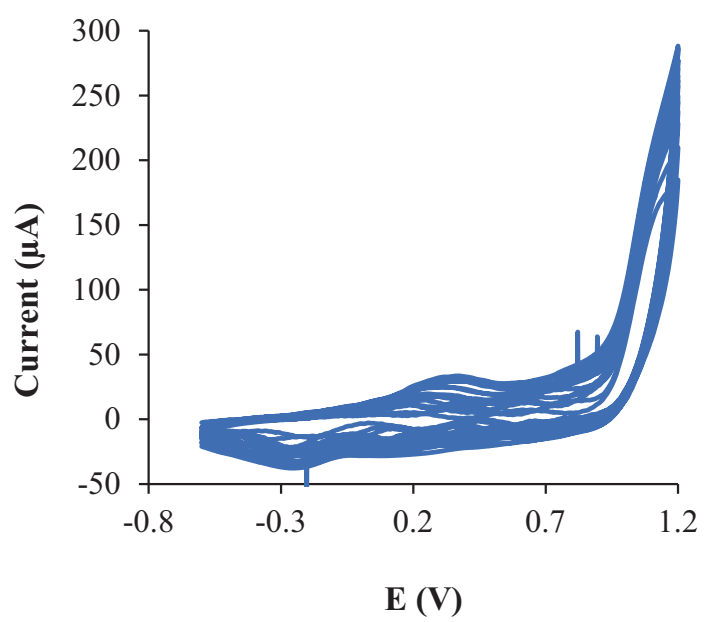

Figure 1. Electropolymerization of AuNPs-SDBS-PEDOT onto the GCE.

The oxidation potential of PEDOT is more negative in the presence of anionic surfactants than in their absence $[36,37]$. In the present study, noble metal NPs like AuNPs have been utilized and can be grown inside the polymeric matrix to improve the performances of the resulting composite material. The surfactants (SDBS) have an effectiveness in the electroanalysis of biological compounds. Also, they have a high effect in the enhancement of the electrode/solution interface properties [38]. Anionic surfactants provide an interesting solvent system for the solubilization of thiophene derivatives. In addition, they affect the electrochemical reactions and also stabilize cation or/and anion radicals [36]. Sakmeche et al [37] have reported the use of an aqueous anionic micellar medium to electrosynthesize well-organized and conducting PEDOT films. It was shown that the electrocatalytic had improved the structural properties of PEDOT films obtained in the presence of the anionic surfactant. A negatively charged film with hydrophilic groups will form through the interaction of the sulphonic group and $\mathrm{Au}$ in the presence of the SDBS surfactant which can cause some changes in the electrode overvoltage and affect the rate of electron transfer [39]. $\mathrm{HAuCl}_{4}$ is used as the oxidant in aqueous medium [40]. For removal of physically adsorbed molecules, the modified GCE was washed with distilled water. Then, dried $8 \mu 1$ of $\operatorname{MWCNT}-\mathrm{COOH}\left(1 \mathrm{mg} \mathrm{ml}^{-1}\right), 8 \mu \mathrm{l}$ of $\operatorname{EDC}(0.5 \% \mathrm{w} / \mathrm{v}), \mathrm{NHS}$ $(0.5 \% \mathrm{w} / \mathrm{v})$ and $\mathrm{Lac}\left(3 \mathrm{mg} \mathrm{ml}^{-1}, \mathrm{pH} 6\right)$ were dropped on the electrode surface, respectively. After drying, the fabricated biosensor was investigated by SEM and FTIR. Moreover, CV techniques were applied to investigate the electrochemical behaviours of catechol. The biosensor was kept in the refrigerator at $4^{\circ} \mathrm{C}$ when it was not used.

\subsection{Characterization of immobilized Lac by different techniques}

Voltammetry techniques were used to study electrochemical biosensor performances in the presence or absence of catechol. Electrochemical experiments were conducted with an electroanalyser, SAMA 500. A conventional cell and three electrodes, $\mathrm{GCE}, \mathrm{Ag} / \mathrm{AgCl}$ (saturated) reference electrode and platinum auxiliary electrode were used. Recording of CVs was done in the range from -0.5 to $0.8 \mathrm{~V}$ and had a scan rate of $0.1 \mathrm{~V} \mathrm{~s}^{-1}$.

\section{Results and discussion}

\subsection{Morphology of electrodes}

According to figure 2, surface morphological analyses of AuNPs-SDBS-PEDOT/GCE, MWCNT-COOH/AuNPsSDBS-PEDOT/GCE and Lac/MWCNT-COOH/AuNPsSDBS-PEDOT/GCE were observed by SEM. Figure 2a shows the spherical AuNPs. As a result, PEDOT and AuNPs are successfully deposited on the GCE. Also, CNTs were attached well on the matrix (AuNPs, SDBS, PEDOT) as shown in figure $2 \mathrm{~b}$. Moreover, the image obviously demonstrates that MWCNT-COOH were scattered on the AuNPs-SDBS-PEDOT/GCE surface. Covering of AuNPs with many MWCNT-COOH has increased the surface area and facilitated the electron transfer on the electropolymerized electrode. Figure 2c illustrates the Lac spots on the modified GCE. The Lac/MWCNT-COOH/AuNPs-SDBSPEDOT/GCE structure can provide a large efficient surface area for excellent catechol diffusion and improving the response of the electrochemical biosensor.

According to figure $2 \mathrm{~d}$, it demonstrates the infrared absorption spectra of two different electrodes (1) MWCNT$\mathrm{COOH} / \mathrm{GCE}$ and (2) Lac/MWCNT-COOH/GCE, which have been achieved in the range from 400 to $4000 \mathrm{~cm}^{-1}$. The bands in figure $2 \mathrm{~d}$ show the functional groups of MWCNT$\mathrm{COOH}$. As can be seen, the peaks at 1618, 3414 and $1387 \mathrm{~cm}^{-1}$ are related to $\mathrm{C}=\mathrm{O}, \mathrm{O}-\mathrm{H}$ and $\mathrm{C}-\mathrm{O}$, respectively. This accentuates the deposition of MWCNT-COOH on the electrode surface. Peaks in the ranges of 1644 1565 and $1648-1566 \mathrm{~cm}^{-1}$ are broad and related to $\mathrm{N}-\mathrm{H}$ primary amines as shown in figure $2 \mathrm{~d}$. Also, $\mathrm{N}-\mathrm{H}$ absorption (out-of-plane) is seen at $719 \mathrm{~cm}^{-1}$. The $\mathrm{C}-\mathrm{N}$ stretch peak appeared in the range of $1350-1000 \mathrm{~cm}^{-1}$ [41]. As indicated in figure $2 \mathrm{~d}$, it is centred at $1157 \mathrm{~cm}^{-1}$. These data confirm the immobilization of Lac by interaction with MWCNT-COOH on the surface of the electrode. Copper atom $(\mathrm{Cu})$ has vibration at $500 \mathrm{~cm}^{-1}$ and it is clear in figure $2 \mathrm{~d}$.

\subsection{Voltammetric response}

One of the electrochemical techniques is $\mathrm{CV}$ which can be used to study the kinetics of oxidation and reduction reactions and conducting properties at electrodes under carefully controlled conditions. A CV consists of plotting current that flows as a function of the applied potential. Phosphate buffer at $\mathrm{pH} 3$ was used for the following 

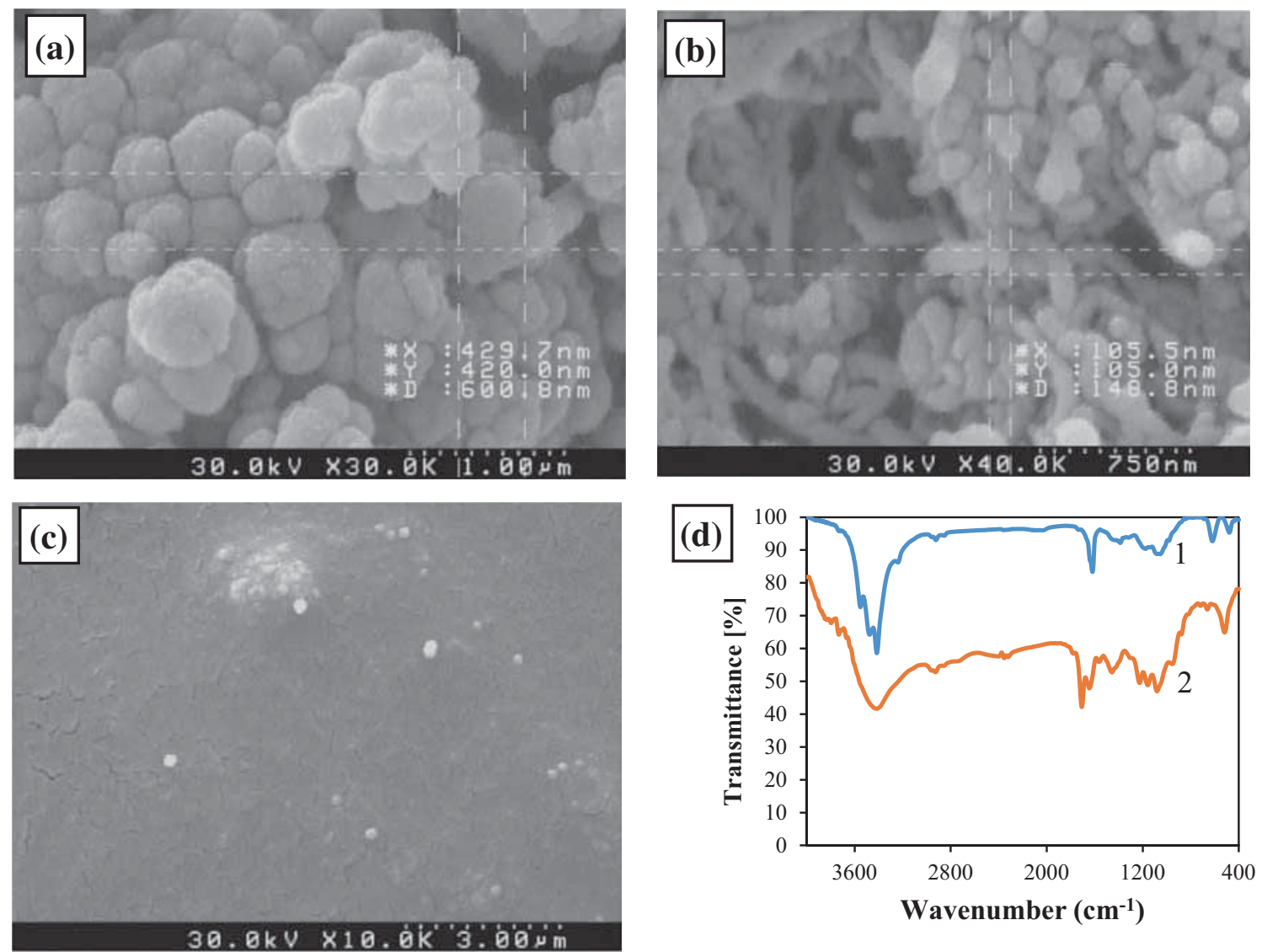

Figure 2. SEM images of modified electrodes: (a) AuNPs-SDBS-PEDOT/GCE, (b) MWCNT-COOH/AuNPs-SDBSPEDOT/GCE, (c) Lac/MWCNT-COOH/AuNPs-SDBS-PEDOT/GCE and (d) FTIR of MWCNT-COOH/GCE (1) and Lac/MWCNT-COOH/GCE (2).

electrochemical measurements. Through the CVs from -0.5 to $0.8 \mathrm{~V}$ at the bare electrode, no evidence of oxidation or reduction peaks can be observed. Nevertheless, with the addition of PEDOT, SDBS, AuNPs, MWCNT-COOH and Lac, the voltammetric response was obtained for the biosensor.

3.2.1 Effect of $p H$ : The proposed biosensor was embraced in buffer solutions of varying $\mathrm{pH}$ values (3-8) (figure 3a). $\mathrm{pH}$ has a great influence on enzymatic reactions. Enzymes have maximal activity at optimal $\mathrm{pH}$. Hence, due to the great effects of $\mathrm{pH}$ on their reactions, the influence of $\mathrm{pH}$ was studied between 3 and 8 on the response of the GCE modified with Lac. According to the type of substrate, the optimal $\mathrm{pH}$ is different [42]; fungal Lac shows optimal activity in the $\mathrm{pH}$ range from 3 to 7 for the phenolic compound [43]. The optimum $\mathrm{pH}$ was found to be 3 and it agrees with previous experiments [44] and native Lac activity [45]. As per pre-reported data, the activity of the Lac enzyme occurs in acidic media. The Lac enzyme will catalyse the oxidation of catechol into the $o$-quinone form followed by reduction of molecular oxygen. The reaction can be schematized as [46]:

Catechol $\stackrel{\text { Enzyme, } \mathrm{O}_{2}}{\longrightarrow}$ o-quinone $+\mathrm{H}_{2} \mathrm{O}$.

The optimum $\mathrm{pH}$ was tested for the biosensor design. To some extent, the response of the biosensor is increased by increasing the current. The Lac biosensor was more responsive in pH 3 buffer solution, since it has a higher current. Then, the current declines for the other different modified electrodes as shown in figure $3 \mathrm{~b}$. As a result, $\mathrm{pH} 3$ was selected for the next experiments at Lac/MWCNT-COOH/AuNPs-SDBSPEDOT/GCE.

3.2.2 Electrochemical behaviour of catechol: The Lac immobilized electrode was tested as a biosensor to detect a phenolic compound like catechol. Determination of catechol was done in the buffer solution at $\mathrm{pH} 3$. We presented the catechol electrochemical behaviour and the oxidation/reduction properties of a material by CV. There are two oxidation and two reduction peak potentials of catechol for each compound which is coated on the surface of 

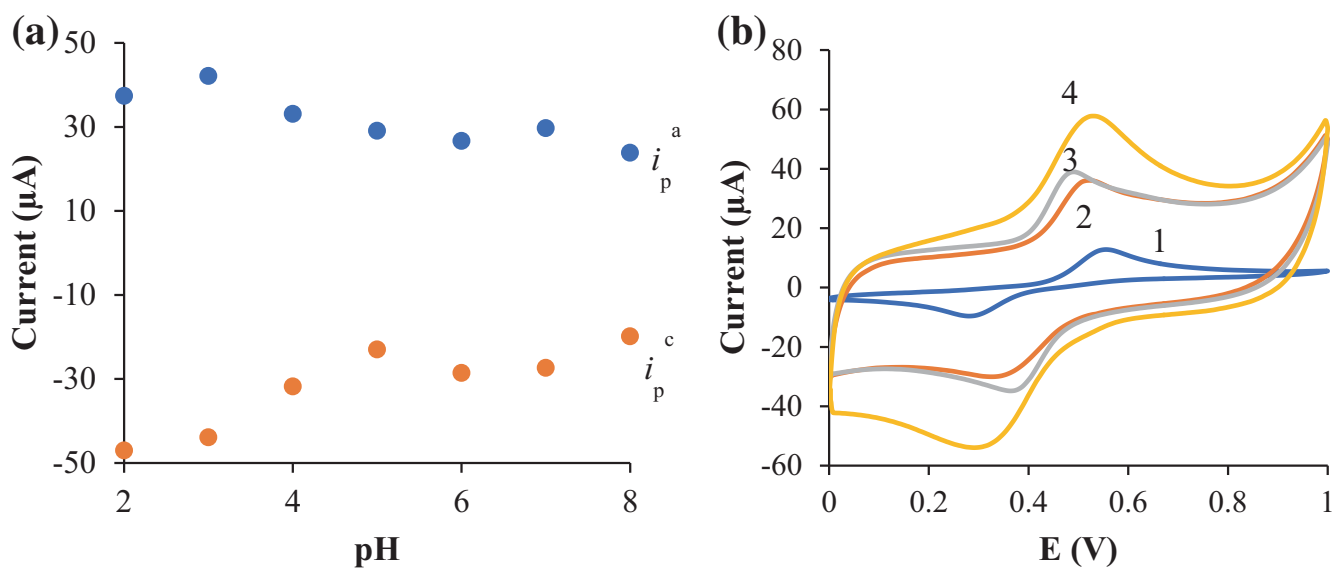

Figure 3. (a) Effect of $\mathrm{pH}$ on the current responses of catechol oxidation and reduction for Lac/MWCNT-COOH/AuNPs-SDBS-PEDOT/GCE. (b) Electrochemical behaviour of catechol onto the GCE (1), AuNPs-SDBS-PEDOT/GCE (2), MWCNT-COOH/AuNPs-SDBS-PEDOT/GCE (3) and Lac/MWCNT-COOH/AuNPs-SDBS-PEDOT/GCE (4) in $0.1 \mathrm{M}$ phosphate buffer at pH 3 containing $1 \mathrm{mM}$ catechol. Scan rate: $0.1 \mathrm{~V} \mathrm{~s}^{-1}$.

Table 1. Anodic and cathodic currents and potentials in $0.1 \mathrm{M}$ phosphate buffer with $\mathrm{pH} 3$ containing $1 \mathrm{mM}$ catechol for GCE and modified electrodes.

\begin{tabular}{lccccc}
\hline \multicolumn{1}{c}{ Electrode } & $i_{\mathrm{p}}^{\mathrm{a}}(\mu \mathrm{A})$ & $i_{\mathrm{p}}^{\mathrm{c}}(\mu \mathrm{A})$ & $E_{\mathrm{p}}^{\mathrm{a}}(\mathrm{V})$ & $E_{\mathrm{p}}^{\mathrm{c}}(\mathrm{V})$ & 0.282 \\
\hline GCE & 10.7 & -8.118 & 0.555 & 0.273 \\
AuNPs-SDBS-PEDOT/GCE & 17.64 & -12.62 & 0.515 & 0.352 \\
MWCNT-COOH/AuNPs-SDBS-PEDOT/GCE & 20.19 & -18.34 & 0.488 & 0.375 \\
Lac/MWCNT-COOH/AuNPs-SDBS-PEDOT/GCE & 31.57 & -27.48 & 0.527 & 0.163 \\
\hline
\end{tabular}

GCE. $E_{\mathrm{p}}^{\mathrm{a}}$ is considered as an anodic peak potential and $E_{\mathrm{p}}^{\mathrm{c}}$ is considered as a cathodic peak potential. $E_{\mathrm{p}}^{\mathrm{a}}$ refers to the catechol oxidation to $o$-quinone and $E_{\mathrm{p}}^{\mathrm{c}}$ refers to the $o$-quinone reduction to catechol. As can be seen in figure 3b, Lac/MWCNT-COOH/AuNPs-SDBS-PEDOT/GCE have the highest anodic and cathodic currents compared to other electrodes. Also, in table 1, the data about $E_{\mathrm{p}}^{\mathrm{a}}$ and $E_{\mathrm{p}}^{\mathrm{c}}$ and also their $i_{\mathrm{p}}^{\mathrm{a}}$ and $i_{\mathrm{p}}^{\mathrm{c}}$ are shown. The proposed Lac biosensor is better (or comparable) than the others, because it demonstrates the highest current due to the maximum catalytic ability for catechol oxidation and reduction. It may also be attributed to the larger specific surface area which can load more Lac molecules to participate in the catalytic reaction.

3.2.3 Effect of scan rate: One of the most important parameters is the investigation of the scan rate effect onto cathodic and anodic potentials and currents, which influences the redox properties of the substrates in CV techniques. So as to examine the result of the scan rate on the biosensor response, $\mathrm{CV}$ was conducted using catechol solution in a series of scan rate values. The voltammograms are shown in figure 4 . The oxidation and reduction peaks enhanced with increasing scan

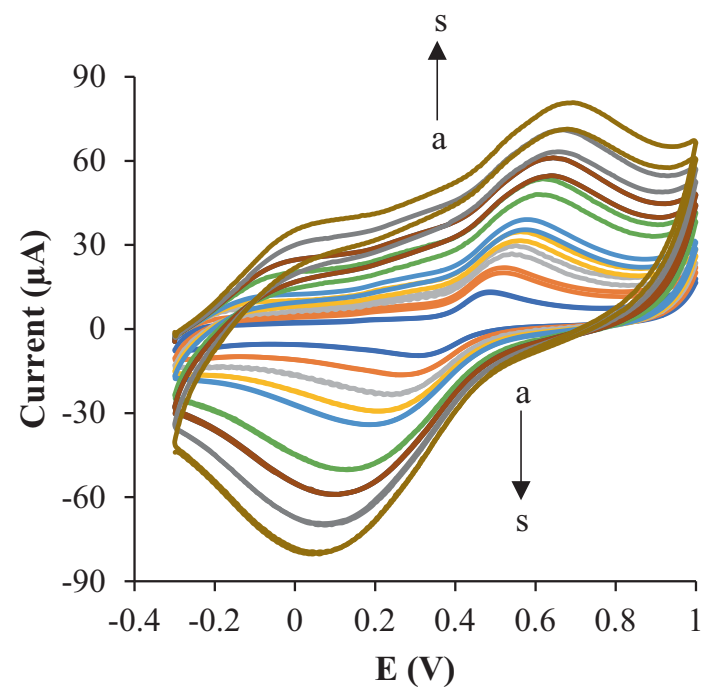

Figure 4. $\mathrm{CV}$ s of Lac/MWCNT-COOH/AuNPs-SDBS-PEDOT/ GCE in $0.1 \mathrm{M}$ phosphate buffer with $\mathrm{pH} 3$ containing $1 \mathrm{mM}$ catechol at different scan rates. Scan rates from (a) to (s) are 0.02, 0.04, $0.06,0.1,0.15,0.2,0.25$ and $0.3 \mathrm{~V} \mathrm{~s}^{-1}$, respectively. 
(a)

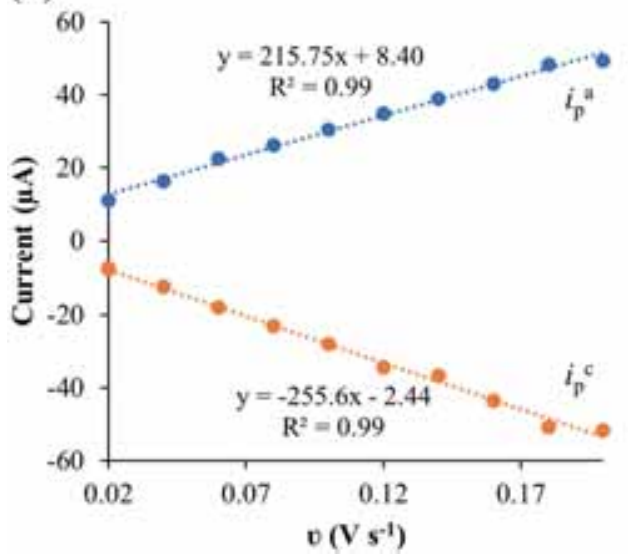

(b)

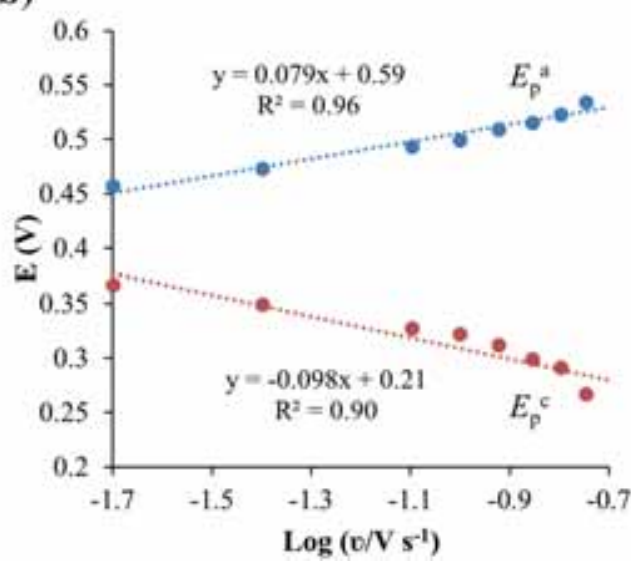

Figure 5. (a) Anodic and cathodic peak currents as a function of scan rate. (b) Dependence of peak potentials $v s$. scan rate at the logarithmic scale. Electrode area: $1.5 \mathrm{~cm}^{2}$; scan rate: $0.1 \mathrm{~V} \mathrm{~s}^{-1}$.
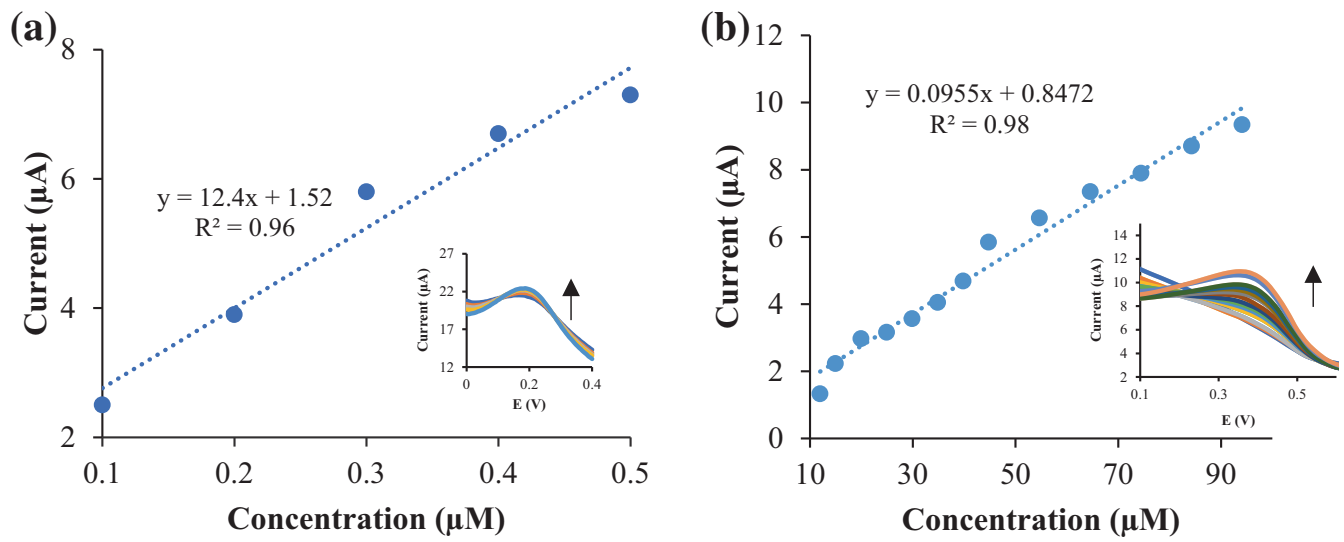

Figure 6. Catechol calibration curves for Lac/MWCNT-COOH/AuNPs-SDBS-PEDOT/GCE (a) at the $E_{\mathrm{p}}^{\mathrm{c}}$ of $0.2 \mathrm{~V}$ and the linear range of $0.1-0.5 \mu \mathrm{M}$ and $(\mathbf{b})$ at the $E_{\mathrm{p}}^{\mathrm{c}}$ of $0.425 \mathrm{~V}$ and the linear range of 11.99$94.11 \mu \mathrm{M}$. Electrode area: $1.5 \mathrm{~cm}^{2}$; scan rate: $0.1 \mathrm{~V} \mathrm{~s}^{-1}$. Inset: DPV curves.

rates and a linear relationship could be found between the scan rate and the peak current with $R^{2}=0.99$ for both anodic and cathodic currents (figure 5a). Increasing scan rate results in adsorption of the substrate to the surface of the electrode.

By increasing the scan rate, the amounts of redox potentials have changed; the cathodic and anodic potentials shifted to negative and positive amounts, respectively (figure 5b). Transfer coefficient $(\alpha)$ and the standard heterogeneous rate constant $\left(k_{\mathrm{s}}\right)$ affect the observed behaviour when the rate of the charge-transfer reaction has changed slowly $[47,48]$.

Figure $5 \mathrm{~b}$ shows the $E_{\mathrm{p}}^{\mathrm{a}}$ and $E_{\mathrm{p}}^{\mathrm{c}}$ relationship with the $\log$ arithm of the scan rate $(\log v)$ for the proposed biosensor in the presence of catechol $(1 \mathrm{mM}) . E_{\mathrm{p}}^{\mathrm{c}}$ changed linearly $v s$. $\log v$ with a linear regression equation of $E_{\mathrm{p}}^{\mathrm{c}}=-0.098 \log v$ $+0.2113 ; R^{2}=0.9\left(v ; \mathrm{V} \mathrm{s}^{-1}\right)$ in the range from 0.02 to $0.2 \mathrm{~V} \mathrm{~s}^{-1}$. The peak potentials can be displayed by Laviron
(1) and (2) for a modified electrode [49]:

$$
\begin{aligned}
E_{\mathrm{p}}^{\mathrm{a}}=E^{0^{\prime}} & -\frac{2.3 R T}{(1-\alpha) n F} \log \frac{(1-\alpha) F n \vartheta}{R T k}, \\
\log k_{\mathrm{s}}= & \alpha \log (1-\alpha)+(1-\alpha) \log \alpha \\
& -\log \frac{R T}{n F \vartheta}-\frac{\alpha(1-\alpha) F n \Delta E_{\mathbf{p}}}{2.3 R T},
\end{aligned}
$$

where $\alpha, n, k, T, R$ and $F$ are the electron transfer coefficient, the number of electrons, heterogeneous electron transfer rate constant, temperature, gas and Faraday constant, respectively. Given that $0.3<\alpha<0.7, \alpha$ and $n$ were found to be 0.7 and 2 , respectively [50]. Consequently, in this redox reaction, two electrons can be transferred. Furthermore, $k_{\mathrm{s}}$ was estimated to be $0.17 \mathrm{~s}^{-1}$, indicating that the electron transfer step in this biosensor has a bigger $k_{\mathrm{s}}$ compared to the literature [45]. 
Table 2. Comparable methods for determination of catechol.

\begin{tabular}{|c|c|c|c|c|}
\hline Biosensor & Linear range $(\mu \mathrm{M})$ & Sensitivity $\left(\mu \mathrm{A} \mathrm{mM}^{-1}\right)$ & Detection limit $(\mu \mathrm{M})$ & Reference \\
\hline \multirow{2}{*}{$\begin{array}{l}\text { Lac/MWCNT-COOH/AuNPs-SDBS- } \\
\text { PEDOT/GCE }\end{array}$} & $0.1-0.5$ & 12.4 & 0.11 & \multirow[t]{2}{*}{ This work } \\
\hline & 11.99-94.11 & 0.0955 & 12.26 & \\
\hline Lac/dithienotetraphenylsilane/PtE & $5.0-200$ & 2.86 & 0.04 & {$[51]$} \\
\hline $\mathrm{Cu} / \mathrm{CNF} / \mathrm{Lac} / \mathrm{Nafion} / \mathrm{GCE}$ & $1-1310$ & 41 & 0.63 & {$[52]$} \\
\hline Chitosan/Si-ZrO $2 / \mathrm{Lac} / \mathrm{GCE}$ & $1.0-100$ & - & 0.35 & [53] \\
\hline Lac/GA/PANI/GCE & $3.2-19.6$ & 0.706 & 2.07 & [45] \\
\hline Lac/ZNZ/GCE & $0.1-100$ & - & 0.035 & [54] \\
\hline
\end{tabular}

Carbon nanofibres, CNFs; polyaniline, PANI; glutaraldehyde, GA; ZnS:Ni/ZnS quantum dots, (ZNZ)QDs.

Table 3. Response of the biosensor in the presence of probable interferences.

\begin{tabular}{lc}
\hline Species & $C_{\text {species }} / C_{\text {catechol }}$ \\
\hline $\mathrm{Na}^{+}, \mathrm{K}^{+}, \mathrm{Br}^{-}, \mathrm{Cl}^{-}$ & 100 \\
Alanine, glycine, glucose, citric acid & 100 \\
Hydroquinone, pyrogallol & 2 \\
\hline
\end{tabular}

3.2.4 Calibration: DPV was applied for the direct catechol detection. Figure 6 shows the relationship between the catechol concentration and the biosensor currents at $\mathrm{pH} 3$ in 1 to $-0.5 \mathrm{~V}$ by DPV for Lac/MWCNT-COOH/AuNPs-SDBSPEDOT/GCE. The response current is linear with catechol concentration in the range from 0.1 to 0.5 related to the peak at the potential of $0.2 \mathrm{~V}$ and $11.99-94.11 \mu \mathrm{M}$ related to the peak at the potential of $0.425 \mathrm{~V}$. The sensitivity for the first and second linear ranges was 12.4 and $0.0995 \mu \mathrm{A} \mathrm{mM}^{-1}$, respectively. The limits of detection were obtained to be 0.11 and 12.26 $\mu \mathrm{M}$. In table 2, the behaviour of the proposed biosensor is compared with the other biosensors based on Lac immobilized in different matrices [45,51-54]. Compared to some other biosensors, the detection limit of our presented biosensor for catechol detection is much lower and also its sensitivity is higher.

3.2.5 Investigation of proposed biosensor in presence of interferences and in a real sample: The proposed Lac biosensor was checked in the presence of various molecules that may interfere with the biosensor response, including cationic and anionic species, glucose, citric acid, some amino acids and a phenolic compound. According to table 3, catechol can be detected without the interfering effect of these molecules with a concentration ratio of 1:100, except for hydroquinone and pyrogallol (the ratio was $1: 2$ ). There were two isolated peaks when hydroquinone or pyrogallol was added to the solution containing catechol.

To investigate the biosensor behaviour in the real sample, lab water was used and catechol was spiked to it. According to table 4 , the recoveries of two estimated catechol concentrations are acceptable amounts.
Table 4. Real sample analysis for catechol detection.

\begin{tabular}{|c|c|c|c|}
\hline Sample & $\begin{array}{l}\text { Spiked catechol } \\
\text { concentration }(\mu \mathrm{M})\end{array}$ & $\begin{array}{l}\text { Detected catechol } \\
\text { concentration }(\mu \mathrm{M})\end{array}$ & Recovery (\%) \\
\hline 1 & 50 & 50.80 & 101.61 \\
\hline 2 & 60 & 63.95 & 106.59 \\
\hline
\end{tabular}

\section{Conclusions}

In this paper, the immobilization of Lac on the modified GCE via the covalent binding method was studied. By manipulating the electrochemical properties of catechol and the Lac catalytic properties besides the great electrochemical properties of MWCNT-COOH, AuNPs and the surfactant, a novel electrochemical procedure was developed for the selective detection of catechol with Lac/MWCNT-COOH/AuNPsSDBS-PEDOT/GCE. The characterization of the fabricated electrode has been performed by FTIR spectroscopy, SEM and voltammetry techniques. FTIR indicated that Lac was immobilized on the modified electrode surface by covalent binding. The proposed biosensor combines the PEDOT properties with the attractive electrocatalytic properties of AuNPs, SDBS and MWCNT-COOH to promote a faster electron transfer rate. This biosensor is able to detect the catechol with low detection limit and high sensitivity.

\section{Acknowledgements}

We gratefully acknowledge the research council of Kermanshah University of Medical Sciences (grant no. 96652) for the financial support.

\section{References}

[1] Gomes S A and Rebelo M J 2003 Sensors 3166

[2] Apetrei I M, Bahrim G and Rodriguez-Mendez M 2012 Rom. Biotechnol. Lett. 177684 
[3] Yang M, Yang Y, Liu Y, Shen G and Yu R 2006 Biosens. Bioelectron. 211125

[4] Girard-Egrot A P, Godoy S and Blum L J 2005 Adv. Colloid Interface Sci. 116205

[5] Apetrei I M and Apetrei C 2013 Int. J. Nanomed. 84391

[6] Sołoducho J and Cabaj J 2010 Sensors 1010298

[7] Cock L S, Arenas A M Z and Aponte A A 2009 Chilean J. Agric. Res. 69270

[8] Jędrychowska A, Malecha K, Cabaj J and Sołoducho J 2015 Electrochim. Acta 165372

[9] Park C S, Lee C and Kwon S 2016 Polym. 8249

[10] Yoon H 2013 Nanomaterials 3524

[11] Park E S, Jang D H, Lee Y I, Jung C W, Lim D, Kim B S et al 2014 Res. Chem. Intermed. 402565

[12] Gerard M, Chaubey A and Malhotra B 2002 Biosens. Bioelectron. 17345

[13] Soylemez S, Kanik F E, Nurioglu A G, Akpinar H and Toppar L 2013 Sens. Actuators B 182322

[14] Gholami M, Nia P M and Alias Y 2015 Appl. Surf. Sci. 357 806

[15] Otrokhov G V, Morozova O V, Vasil'eva I S, Shumakovich G P, Zaitseva E A and Khlupova M E 2013 Biochem. (Mosc) 78 1539

[16] Luo X, Morrin A, Killard A J and Smyth M R 2006 Electroanalysis 18319

[17] Luz R A, Iost R M and Crespilho F N 2013 Nanobioelectrochemistry (Berlin, Heidelberg: Springer) p 27

[18] Holzinger M, Le Goff A and Cosnier S 2014 Front. Chem. 27 63

[19] Hou S, Zhang A and Su M 2016 Nanomaterials 658

[20] Balasubramanian K and Burghard M 2006 Anal. Bioanal. Chem. 385452

[21] Malik P, Katyal V, Malik V, Asatkar A, Inwati G and Mukherjee T K 2013 ISRN Nanomaterials 2013, Article ID 327435, 1

[22] Wang J 2005 Analyst 130421

[23] Tîlmaciu C M and Morris M C 2015 Front. Chem. 359

[24] Zhu C, Yang G, Li H, Du D and Lin Y 2014 Anal. Chem. 87 230

[25] Zestos A G, Jacobs Ch B, Trikantzopoulos E, Ross A E and Venton B J 2014 Anal. Chem. 868568

[26] Baghbamidi S E, Beitollahi H, Karimi-Maleh H, SoltaniNejad S, Soltani-Nejad V and Roodsaz S 2012 J. Anal. Meth. Chem. 2012, Article ID 305872, 1

[27] Rodríguez-Delgado M M, Alemán-Nava G S, RodríguezDelgado J M, Dieck-Assad G, Martínez-Chapa S O and Barceló D 2015 Trends Anal. Chem. $\mathbf{7 4} 21$

[28] Li Y, Schluesener H J and Xu S 2010 Gold Bull. 4329

[29] Mo D, Zhou W, Ma X, Xu J, Jiang F and Zhu D 2015 Electrochim. Acta 151477

[30] Madhavi V and Lele S 2009 Bioresources 41694
[31] Hua Z, Qin Q, Bai X, Wang C and Huang X 2015 Sens. Actuators $B 2201169$

[32] Sharma P, Goel R and Capalash N 2007 World J. Microbiol. Biotechnol. 23823

[33] Singh S, Jain D V S and Singla M L 2013 Sens. Actuators B 182 161

[34] Li Y, Zhang L, Li M, Pan Z and Li D 2012 Chem. Cent. J. 6 103

[35] de Souza Ribeiro F A, Tarley C R T, Borges K B and Pereira A C 2013 Sens. Actuators B 185743

[36] Sakmeche N, Aeiyach S, Aaron J-J, Jouini M, Lacroix J C and Lacaze P-C 1999 Langmuir 152566

[37] Sakmeche N, Aaron J-J, Aeiyach S and Lacaze P-C 2000 Electrochim. Acta 451921

[38] Atta N F, Galal A and El-Ads E H 2014 Int. J. Electrochem. Sci. 92113

[39] Li C, Ya Y and Zhan G 2010 Colloids Surf. B: Biointerfaces 76 340

[40] Guo Q, Zou S, Li J, Li D, Jiao H and Shi J 2014 J. Nanopart. Res. 161

[41] Pavia D L, Lampman G M, Kriz G S and Vyvyan J A 2014 Introduction to spectroscopy, 5th edn. (USA: Cengage Learning)

[42] Desai S S and Nityanand C 2011 Asian J. Biotechnol. 398

[43] Bollag J M and Leonowicz A 1984 Appl. Env. Microbiol. 48 849

[44] Ferreira M S, Silva Filho A F, Martins V L, Andrade M M, Giarola D A and Dall'Antonia L H 2015 Acta Sci-Technol. 37 265

[45] Nazari M, Kashanian S and Rafipour R 2015 Spectrochim. Acta A 145130

[46] Portaccio M, Di Martino S, Maiuri P, Durante D, De Lucaa P, Leporea M et al 2006 J. Mol. Catal. B Enzym. 4197

[47] Bard A J, Faulkner L R, Leddy J and Zoski C G 2001 Electrochemical methods: fundamentals and applications, 2nd edn (New York: Wiley)

[48] Rafipour R, Kashanian S, Hashemi S, Shahabadi N and Omedfar K 2015 Biotechnol. Appl. Biochem. 63740

[49] Laviron E 1979 J. Electroanal. Chem. Interf. Electrochem. 101 19

[50] Li G, Sun K, Li D, Lv P, Wang Q, Huang F et al 2016 Coll. Surf. A: Physicochem. Eng. Asp. 509408

[51] Cabaj J, Jędrychowska A, Zając D, Krawiec S and Sołoducho J 2016 Int. J. Electrochem. Sci. 11609

[52] Fu J, Qiao H, Li D, Luo L, Chen K and Wei Q 2014 Sensors 14 3543

[53] Qu J, Wang Y, Guo J, Lou T and Dong Y 2014 Anal. Lett. 47 2537

[54] Wang Y, Qu J, Li S and Qu J 2016 J. Nanosci. Nanotechnol. 16 8302 